\title{
Polymorphisms of eNOS, catalase, and myeloperoxidase genes in prostate cancer in Turkish men: preliminary results
}

G.G. Ceylan¹, C. Ceylan², B. Gülmemmedov², Ş. Tonyalı², O. Odabaş², A. Gözalan ${ }^{3}$, I. Keleş ${ }^{4}$ and E. Öztürk ${ }^{5}$

${ }^{1}$ Department of Medical Genetics, Medical School, Yildirim Beyazit University, Ankara, Turkey

${ }^{2}$ Turkey Yuksek Ihtisas Training and Research Hospital, Department of Urology, Ankara, Turkey

${ }^{3}$ Atatürk Training and Research Hospital, Department of Medical Microbiology, Ankara, Turkey

${ }^{4}$ Department of Urology, Medical School, Afyon Kocatepe University, Afyon, Turkey

${ }^{5}$ Atatürk Training and Research Hospital, Department of Medical Genetics, Ankara, Turkey

Corresponding author: G.G. Ceylan

E-mail: gulayceylan23@gmail.com

Genet. Mol. Res. 15 (3): gmr.15038543

Received February 11, 2016

Accepted March 28, 2016

Published August 18, 2016

DOI http://dx.doi.org/10.4238/gmr.15038543

Copyright $(C 2016$ The Authors. This is an open-access article distributed under the terms of the Creative Commons Attribution ShareAlike (CC BY-SA) 4.0 License.

ABSTRACT. Prostate cancer (PCa) is the most common type of neoplasm in European males. Genetic and epigenetic factors contribute to $\mathrm{PCa}$ development and progression. In this study, we aimed to assess the relationship between $\mathrm{PCa}$ and polymorphisms in the genes encoding endothelial nitric oxide synthase (eNOS), catalase (CAT), and myeloperoxidase (MPO). In total, 193 patients were included in 
the study. Patients were divided into three groups: PCa (78), benign prostate hyperplasia (40), and control males (75). The parameters assessed included body mass index (BMI), smoking habits, presence of prostatism, prostate-specific antigen (PSA) levels, Gleason scores of prostate specimens, as well as polymorphisms in eNOS-G894T, CAT262T, and MPO G-463T genes. BMI and smoking status of controls and patient groups showed no significant difference. CAT-262T gene polymorphism was found to be homozygous in $35.4 \%$ of PCa patients, which was 4.02 -fold that in the controls $(\mathrm{P}=0.006)$. There was no statistically significant difference in eNOS-G894T and MPO G-463T gene polymorphisms between any of the groups. In conclusion, we found catalase levels to be associated with PCa diagnosis and PSA value. We did not find any significant differences between groups for other polymorphisms, but we believe that further studies with a large sample size may be needed before drawing definite conclusions.

Key words: Prostate cancer; Polymorphism; Catalase; Myeloperoxidase; Endothelial nitric oxide synthetase

\section{INTRODUCTION}

Prostate cancer $(\mathrm{PCa})$ is the most common type of solid neoplasm in Europe, with an incidence of 214 cases per 1000 males (Heidenreich et al., 2014). There has been a steady increase in the incidence of PCa over the last 20 years. This may be due to the extensive use of effective screening tools, such as prostate-specific antigen (PSA) (Plata Bello and Concepcion Masip, 2014).

The etiology of $\mathrm{PCa}$ is still unknown, although age, ethnicity, and heredity are three well-established risk factors. The risk of developing PCa doubles if one's first-line relative has $\mathrm{PCa}$; this risk increases by 5-11-fold if two or more first-line relatives are affected (Heidenreich et al., 2014). These findings suggest that genetic factors play a role in the pathophysiology of PCas. In addition, epigenetic factors have also been shown to contribute to PCa development and progression (Konishi et al., 2005; Yu and Luo, 2007).

Over the last decade, it has been confirmed that oxidative stress is associated with the development and progression of PCa. Oxidative stress occurs due to increased reactive oxygen species (ROS), such as hydroxyl radicals, peroxides, and superoxides. Elevated ROS level may lead to tissue and DNA damage, and may be the result of infections, aging, neoplastic transformation, as well as abnormal growth and cell proliferation (Khandrika et al., 2009). Both excessive production of ROS and inadequate antioxidant activity lead to increased ROS. Therefore, genetic alterations in antioxidant enzymes or enzymes responsible for the production of ROS may affect the risk of developing cancer (Konishi et al., 2005; Yu and Luo, 2007, Khandrika et al., 2009).

The aim of this study was to assess the relationship between PCa and polymorphisms in the genes encoding endothelial nitric oxide synthase (eNOS), catalase (CAT), and myeloperoxidase (MPO).

\section{MATERIAL AND METHODS}

In total, 193 patients were enrolled into the study between September 1, 2014 and

Genetics and Molecular Research 15 (3): gmr.15038543 
October 1, 2015. They came to our hospital either for routine check-ups, or were admitted due to low urinary tract symptoms (LUTS), or had undergone a transurethral resection of the prostate (TUR-P) for benign prostate hyperplasia (BPH) and radical prostatectomy (RP) for PCa. Patients diagnosed with chronic prostatitis and patients who had undergone radiotherapy, hormonotherapy, and brachytherapy for $\mathrm{PCa}$ were excluded from the study. The patients were divided into three groups: those who had undergone $\mathrm{RP}$ for $\mathrm{PCa}$, those who had undergone TUR-P for BPH, and those without LUTS. There were 78, 40, and, 75 patients in first, second, and third groups, respectively. Approval from the local Ethics Committee and written informed consents were obtained from all study subjects prior to enrolment. The parameters examined included body mass index (BMI), smoking habits, presence of LUTS (prostatism), PSA levels, and Gleason scores (GS) of RP specimens.

Patients were divided into two groups according to BMI: BMI $>26 \mathrm{~kg} / \mathrm{m}^{2}$ and BMI $<$ $26 \mathrm{~kg} / \mathrm{m}^{2}$. Patients were also divided into subgroups based on GS (GS $\leq 6$ and GS $\geq 7$ ), PSA levels (PSA $\leq 10 \mathrm{ng} / \mathrm{mL}$ and PSA $\geq 10 \mathrm{ng} / \mathrm{mL}$ ), the presence or absence of biochemical (PSA) recurrences, as well as $\mathrm{T}$ stages ( $\mathrm{T} \leq 2$ and $\mathrm{T}>2$ ). PSA levels were measured using the Human PSA ELISA kit (RayBio ${ }^{\circledR}$, USA). Blood samples obtained from patients and controls were stored at $4^{\circ} \mathrm{C}$ in EDTA tubes for genetic examination.

\section{Genetic examination}

\section{Genotyping for the eNOS-G894T polymorphism}

In total, $5 \mathrm{~mL}$ blood from each patient was taken for genetic analysis. DNA extraction was performed via a commercial kit (QIAamp DNA mini kit; Qiagen, Hilden, Germany). For the detection of G894T polymorphisms on the eNOS gene, a part of the eNOS gene containing exon 7 was amplified using polymerase chain reaction (PCR) with the following flanking intronic primers: sense 5'-CATGAGGCTCAGCCCCAGAAC-3' and antisense 5'-AGTCAATCCCTTTGGTGCTCAC-3'. This was followed by $M b o$ I restriction endonuclease digestion for $16 \mathrm{~h}$ at $37^{\circ} \mathrm{C}$, after which electrophoresis was carried out on a $3 \%$ agarose gel. DNA fragments were visualized under UV light following ethidium bromide staining. The presence of G894T polymorphism will result in the cleavage of the 206-bp PCR product into two fragments (119 and $87 \mathrm{bp}$ ).

\section{Genotyping for CAT-262C $\rightarrow$ T polymorphism}

GenotypingfortheCAT-262C $\rightarrow$ Tpolymorphismwasperformedaspreviouslydescribed, with modifications (Forsberg et al., 2001). The associated region on the CAT gene promoter site was amplified with the following primers: 5'-TAAGAGCTGAGAAAGCATAGCT-3' (sense) and 5'-AGAGCCTCGCCCCGCCGGACCG-3' (antisense). The cycling protocol was as follows: $94^{\circ} \mathrm{C}$ for $30 \mathrm{~s}, 68^{\circ} \mathrm{C}$ for $45 \mathrm{~s}, 72^{\circ} \mathrm{C}$ for $1 \mathrm{~min},-0.5^{\circ} \mathrm{C} /$ cycle, 19 times; $94^{\circ} \mathrm{C}$ for 30 $\mathrm{s}, 58^{\circ} \mathrm{C}$ for $45 \mathrm{~s}, 72^{\circ} \mathrm{C}$ for $1 \mathrm{~min}, 25$ times. In addition, $15 \mathrm{~mL}$ of the mixture was incubated with five units of the enzyme in the presence of potassium acetate, Tris-acetate, magnesium acetate, and dithiothreitol buffer. The fragments were stained with ethidium bromide, and were electrophoresed on a $2 \%$ agarose gel.

Genetics and Molecular Research 15 (3): gmr.15038543 


\section{Genotyping for MPO G-463T polymorphism}

Intotal,5mLbloodfromeachpatientwascollectedintoEDTA-containingtubesforgenetic analysis. DNA extraction was performed via a commercial kit (QIAamp DNA mini kit; Qiagen). For the detection of G-463T polymorphisms on the MPO gene, a portion of the MPO promoter was PCR amplified with the following primers: 5'-CGGTATAGGCACACAATGGTGAG-3' (sense) and 5'-GCAATGGTAAAGCGATTCTTC-3' (antisense). AciI restriction endonuclease digestion was carried out for $16 \mathrm{~h}$ at $37^{\circ} \mathrm{C}$, and the products were run on a $3 \%$ agarose gel. Ethidium bromide-stained DNA fragments were examined under UV light.

The 350-bp PCR product was cleaved into three fragments $(169,120$, and $61 \mathrm{bp})$ in samples with the G-463T polymorphism.

\section{Statistical analyses}

Statistical analysis was performed using available licensed commercial statistics program. Visual and analytical methods were used (Kolmogorov-Smirnov test) to determine whether the variables followed normal distributions. Descriptive analyses were presented using the mean and the standard deviation for normally distributed variables. Non-normally distributed variables were described using the median and the interquartile range (IQR). The Pearson $\chi^{2}$ test, the Fisher exact test, the Student $t$-test, and the Mann-Whitney U-test were used to analyze the data, as appropriate. Comparisons between groups were also performed using the odds ratio with a $95 \%$ confidence interval (CI), where $\mathrm{P}<0.05$ was considered to be statistically significant.

\section{RESULTS}

In total, 193 patients were included in the study. The patients were classified into three groups: 78 patients diagnosed with $\mathrm{PCa}, 40$ patients diagnosed with $\mathrm{BPH}$, and 75 control patients. There was no significant difference in age among the three groups (control: $63.1 \pm$ 7.8 years; $\mathrm{BPH}$ : $64.6 \pm 8$ years; $\mathrm{PCa}: 64.9 \pm 6.7$ years; $\mathrm{P}=0.354$ and 0.126 for $\mathrm{BPH}$ and $\mathrm{PCa}$, respectively, as compared to the controls). In total, $65.4 \%$ of the PCa group and $55 \%$ of the $\mathrm{BPH}$ group were smokers, whereas $60 \%$ of the control group were smokers. No significant differences were detected in the smoking habits between the three groups $(\mathrm{P}=0.491$ and 0.605 for $\mathrm{BPH}$ and $\mathrm{PCa}$, respectively, as compared to the controls). The demographic data of the patients are presented in Table 1 . We found that the BMI was $>26 \mathrm{~kg} / \mathrm{m}^{2}$ in $70.5 \%$ of the PCa group, $75 \%$ of the BPH group, and $58.7 \%$ of the control group, and there was no significant difference between the control group and the $\mathrm{PCa}$ and $\mathrm{BPH}$ groups $(\mathrm{P}=0.125$, 0.082 , respectively).

In addition, there was no significant difference between the BPH group [0.30 (IQR $=$ $0.15)]$ and the control group $[0.34(\mathrm{IQR}=0.2)]$ with respect to median free/total PSA levels $(\mathrm{P}=0.055)$. However, the median $\mathrm{F} / \mathrm{T}$ PSA ratio of the PCa group $[0.14(\mathrm{IQR}=0.07)]$ was significantly lower than that of the control group $[0.34(\mathrm{IQR}=0.2)](\mathrm{P}=0.001)$.

Homozygosity of the CAT-262T gene was found in $35.4 \%$ of PCa patients, which was 4.02-fold higher than the controls $(\mathrm{P}=0.006)$. No significant difference was observed between the $\mathrm{BPH}(23.8 \%)$ and control $(12 \%)$ groups $(\mathrm{P}=0.282)$.

There was no statistically significant difference between the three groups in the

Genetics and Molecular Research 15 (3): gmr.15038543 
homozygosity and heterozygosity of eNOS G894T and MPO G-463T genes. The detailed genotypes of patients from each group are listed in Table 2. Lastly, there was no association between the genetic polymorphisms and the GS and grades (Table 3).

Table 1. Demographic data of all study groups.

\begin{tabular}{|c|c|c|c|}
\hline & Control $(\mathrm{N}=75)$ & $\mathrm{BPH}(\mathrm{N}=40)$ & $\mathrm{PCa}(\mathrm{N}=78)$ \\
\hline Age [years (means)] & $53.20(\mathrm{SD}=14.7)$ & $66.7(\mathrm{SD}=9.3)$ & $64.9(\mathrm{SD}=6.7)$ \\
\hline f/t range (median) & $0.34(\mathrm{IQR}=0.2)$ & $0.30(\mathrm{IQR}=0.15)$ & $0.14(\mathrm{IQR}=0.07)$ \\
\hline \multicolumn{4}{|l|}{ eNOS } \\
\hline Normal & $47(62.7 \%)$ & $20(50.0 \%)$ & $46(59.0 \%)$ \\
\hline Heterozygote & $23(30.7 \%)$ & $17(42.5 \%)$ & $23(29.5 \%)$ \\
\hline Homozygote & $5(6.7 \%)$ & $3(7.5 \%)$ & $9(11.5 \%)$ \\
\hline \multicolumn{4}{|l|}{ Catalase } \\
\hline Normal & $44(58.7 \%)$ & $16(40.0 \%)$ & $31(39.7 \%)$ \\
\hline Heterozygote & $25(33.3 \%)$ & $19(47.5 \%)$ & $30(38.5 \%)$ \\
\hline Homozygote & $6(8.0 \%)$ & $5(12.5 \%)$ & $17(21.8 \%)$ \\
\hline \multicolumn{4}{|l|}{ MPO } \\
\hline Normal & $36(48 \%)$ & $19(47.5 \%)$ & $48(61.5 \%)$ \\
\hline Heterozygote & $40(40.0 \%)$ & $17(42.5 \%)$ & $24(30.8 \%)$ \\
\hline Homozygote & $9(12.0 \%)$ & $4(10.0 \%)$ & $6(7.7 \%)$ \\
\hline \multicolumn{4}{|l|}{ Smoking } \\
\hline Yes & $45(60.0 \%)$ & $22(55.0 \%)$ & $51(65.4 \%)$ \\
\hline No & $30(40.0 \%)$ & $18(45.0 \%)$ & $27(34.6 \%)$ \\
\hline \multicolumn{4}{|l|}{ BMI } \\
\hline$\leq 26$ & $31(41.3 \%)$ & $10(25.0 \%)$ & $23(29.5 \%)$ \\
\hline$>26$ & $44(58.7 \%)$ & $30(75.0 \%)$ & $55(70.5 \%)$ \\
\hline
\end{tabular}

Table 2. eNOS, CAT and MPO gene polymorphisms in all subject groups.

\begin{tabular}{|c|c|c|c|c|c|c|c|c|}
\hline \multirow[t]{2}{*}{ Polymorphism } & \multicolumn{4}{|c|}{ Heterozygote } & \multicolumn{4}{|c|}{ Homozygote } \\
\hline & N (\%) & Odds ratio & $95 \% \mathrm{CI}$ & $P$ value & N (\%) & Odds ratio & $95 \% \mathrm{CI}$ & P value \\
\hline \multicolumn{9}{|l|}{ eNOS } \\
\hline $\mathrm{PCa}$ & $23 / 69$ (33.3) & 1.02 & $0.50-2.07$ & 0.952 & $9 / 55(16.4)$ & 1.84 & $0.57-5.90$ & $0.301 *$ \\
\hline $\mathrm{BPH}$ & $17 / 37$ (45.9) & 1.74 & $0.77-3.93$ & 0.183 & $3 / 23(13.0)$ & 1.41 & $0.31-6.47$ & $0.695^{*}$ \\
\hline Control & $23 / 70(32.9)$ & 1 & & & $5 / 52(9.6)$ & 1 & & \\
\hline \multicolumn{9}{|l|}{ CAT } \\
\hline $\mathrm{PCa}$ & $30 / 61$ (49.2) & 1.70 & $0.84-3.44$ & 0.136 & $17 / 48(35.4)$ & 4.02 & $1.42-11.36$ & 0.006 \\
\hline $\mathrm{BPH}$ & $19 / 35(54.3)$ & 2.10 & $0.91-4.78$ & 0.078 & $5 / 21(23.8)$ & 2.29 & $0.61-8.56$ & $0.282 *$ \\
\hline Control & $25 / 69(36.2)$ & 1 & & & $6 / 50(12.0)$ & 1 & & \\
\hline \multicolumn{9}{|l|}{ MPO } \\
\hline $\mathrm{PCa}$ & $24 / 72(33.3)$ & 0.60 & $0.30-1.20$ & 0.145 & $6 / 54$ (11.1) & 0.50 & $0.16-1.53$ & 0.219 \\
\hline $\mathrm{BPH}$ & $17 / 36(47.2)$ & 1.07 & $0.48-2.42$ & 0.864 & $4 / 23(17.4)$ & 0.84 & $0.23-3.10$ & $1.000^{*}$ \\
\hline Control & $30 / 66(45.5)$ & 1 & & & $9 / 45(20.0)$ & 1 & & \\
\hline
\end{tabular}

*Using Fisher exact test. $\mathrm{CI}=$ confidence interval.

\section{DISCUSSION}

$\mathrm{PCa}$ is the most common cancer in European males and the second most common cancer in males worldwide (Heidenreich et al., 2014; Plata Bello and Concepcion Masip, 2014). There has been a steady increase in its incidence over the last two decades, which may be due to the progressively aging population as well as strict screening programs. 
Table 3. Distribution of gene polymorphisms according to Gleason score and T stages in the patient group.

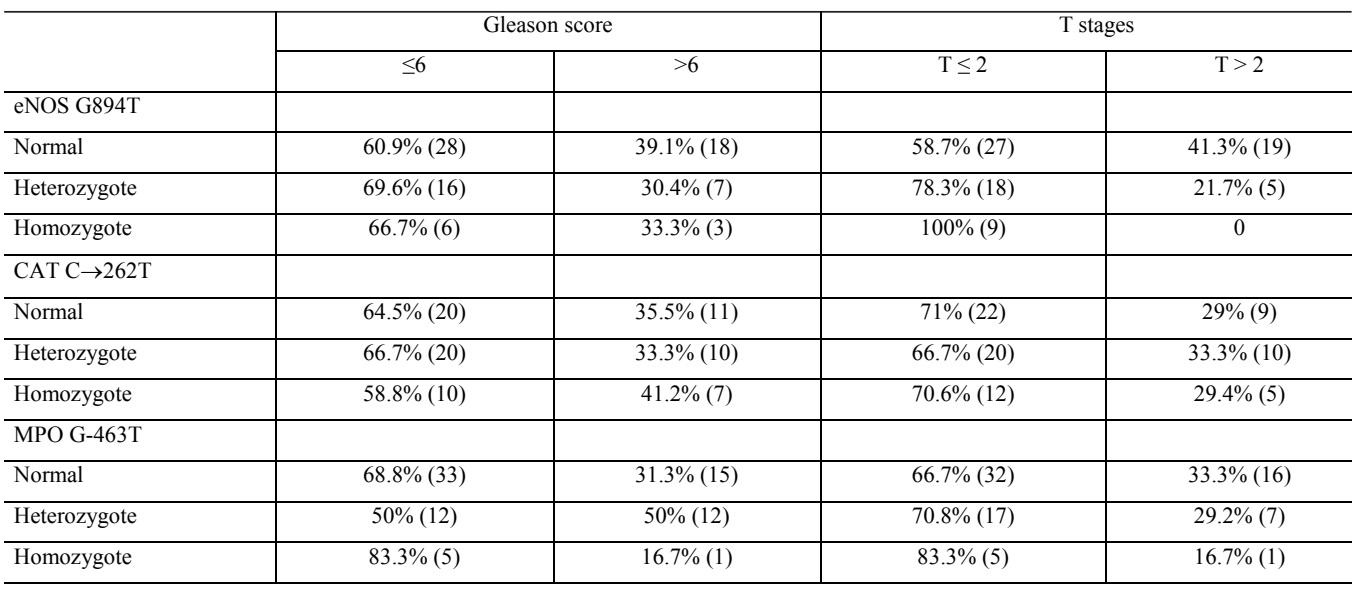

The incidence and mortality of PCa vary geographically; genetic and environmental factors may explain these differences (Plata Bello and Concepcion Masip, 2014).

Obesity was found to be associated with increased risk of advanced PCa and higher PCa-specific mortality (Vidal et al., 2014). However, a study by Møller et al. (2015) showed that the incidence of PCa was found to be similar or even slightly lower in obese men as compared to non-obese males. Smoking was proposed to be another risk factor for PCa. However, its exact role in PCa pathogenesis remains unclear (Shahabi et al., 2014). It was suggested that smoking may contribute to $\mathrm{PCa}$ development and progression by causing oxidative stress (Cheng et al., 2011; Rohrmann et al., 2013). On the other hand, some studies also suggested that smoking reduces the risk of localized and low-grade PCa (Rohrmann et al., 2013). In our study, we found no statistically significant differences between the $\mathrm{PCa}, \mathrm{BPH}$, and control groups in terms of BMI and smoking.

Nitric oxide synthase (NOS) gene polymorphisms have been shown to be associated with PCa, particularly with aggressive types of cancer (stages III-IV or GS $\geq 7$ ) (Lee et al., 2009a). The MPO G-463A gene polymorphism was found to be associated with increased risk of aggressive PCa among smokers with low $\alpha$-tocopherol levels (Cheng et al., 2011). In addition, Geybels et al. (2015) observed an association between CAT rs1001179 gene polymorphism and aggressive PCa (both stages III and IV).

Oxidative stress is a consequence of aerobic mechanisms in human, and it is known to be associated with aging and age-related diseases, such as PCa. A kinetic equilibrium exists between ROS and the antioxidant machinery in the cell under normal circumstances. When ROS levels exceed the antioxidant capacity of the cell, oxidative stress occurs, which may lead to ROS (i.e., superoxide radicals, hydrogen peroxide, and hydroxyl radicals)-induced DNA damage (Battisti et al., 2011).

Nitric oxide is a free radical synthesized from L-arginine by NOS. NOS has numerous physiological and pathological functions in the cardiovascular system, the nervous system, the immune system, and during carcinogenesis (Safarinejad et al., 2013; Haque et al., 2015). The NOS family includes three isoenzymes: eNOS, inducible NOS (iNOS), and neuronal NOS (nNOS). eNOS is expressed in endothelial cells, and genetic polymorphisms of eNOS have

Genetics and Molecular Research 15 (3): gmr.15038543 
been extensively studied in erectile dysfunctions (Lee et al., 2009b) and cancers, such as PCa and bladder cancer (Wartenberg et al., 2003; Tong and Li, 2004; Zhang et al., 2014; Polat et al., 2015). Deregulated eNOS was found to be associated with aging and several cancers, such as pancreatic cancer and PCa (Nanni et al., 2013).

In our study, we found that eNOS-G894T homozygosity was higher in the PCa group as compared with the BPH and control groups, at $16.4 v s 13$ and $9.6 \%$, respectively. However, these differences were not statistically significant. Furthermore, no significant difference was detected between either of the experimental groups and the control group in eNOS-G894T homozygosity and heterozygosity.

In addition to aging, life-long exposure to ROS can also contribute to PCa. ROS facilitates mitochondrial permeability via glutathione and many pro-oxidant and antioxidant enzymes, such as CAT, MPO, and superoxide dismutase (SOD2) (Ding et al., 2012). It has been shown that patients with $\mathrm{PCa}$ and prostatic intraepithelial neoplasia have reduced expressions of SOD1, SOD2, and CAT as compared with healthy subjects (Bostwick et al., 2000).

MPO is an oxidative lysosomal enzyme present in neutrophils and monocytes, and it can bio-activate various specific pro-carcinogens, such as polycyclic aromatic hydrocarbons and aromatic amines (Arslan et al., 2011).

Genetic polymorphisms have been thought to contribute to the etiopathogenesis in various cancers. The MPO G-463A polymorphism was shown to be associated with various cancer types, including lung cancer (Dally et al., 2002; Kiyohara et al., 2005). However, few have studied the relationship between MPO G-463A polymorphism and PCa (Choi et al., 2008; Arslan et al., 2011). Choi et al. (2008) observed a reduced risk of aggressive PCa in individuals with the MPO AA genotype as compared to individuals with the MPO GG genotype. Similarly, Cheng et al. (2011) also reported an association between MPO gene polymorphism and PCa aggressiveness in smokers. On the other hand, in a Turkish population-based study, no statistically significant relationship was found between MPO G-463 polymorphism and PCa (Arslan et al., 2011). In our study, we did not find any statistically significant difference between either the PCa or the BPH groups and the controls in MPO G-463 homozygosity and heterozygosity.

CAT serves as an endogenous antioxidant enzyme by converting hydrogen peroxide to oxygen and water. The $\mathrm{T}$ allele of the CAT $(\mathrm{C}-262 \mathrm{~T})$ gene has been shown to be associated with reduced enzyme production as compared with the $\mathrm{C}$ allele. The activity of CAT, which is an essential antioxidant, was found to be significantly diminished in PCa patients. There are conflicting results in the literature regarding the role of the CAT (C-262T) gene polymorphism in PCa (Choi et al., 2007; Battisti et al., 2011; Karunasinghe et al., 2012; Tefik et al., 2013; Geybels et al., 2015; Hu et al., 2015). Geybels et al. (2015) suggested that CAT gene polymorphism is associated with stage III/IV prostate cancers. In addition, Karunasinghe et al. (2012) found a significant association between the C-262T allele and increased risk to PCa. In accordance with these results, Tefik et al. (2013) found that CAT $\mathrm{C}-262 \mathrm{~T}$ polymorphism is associated with increased risk to PCa. Interestingly, some studies have reported no association between CAT polymorphism and PCa (Choi et al., 2007; Ding et al., 2012). In our study, CAT-262T homozygosity was found to be significantly higher in the $\mathrm{PCa}$ group as compared with the controls, at 35.4 and $12 \%$, respectively $(\mathrm{P}=0.006)$. In addition, there was also a slight difference between the BPH group and controls in CAT$262 \mathrm{~T}$ homozygosity, at 23.8 and $12 \%$, respectively $(\mathrm{P}=0.282)$. No statistically significant difference was observed between both the PCa and BPH groups and the control group for CAT-262 heterozygosity (49.2, 54.3, and $36.2 \%$, respectively).

Genetics and Molecular Research 15 (3): gmr.15038543 
PCa is the most common type of cancer among males, and several attempts have been made to determine the predictive value of biochemical markers in its diagnosis. In addition, developments in the field of cancer genetics have improved our knowledge of many cancers, including PCa. This study examined polymorphisms in three enzyme genes (eNOS G894T, CAT 262T, and MPO G-463), which may induce or suppress PCa in patients diagnosed with $\mathrm{PCa}$ and who had undergone radical prostatectomy, as well as in healthy controls and patients who were diagnosed with BPH. Among these markers, CAT was found to be associated with $\mathrm{PCa}$ diagnosis and PSA values. We did not detect any significant difference among the three groups for the other gene polymorphisms. However, more studies with larger sample sizes are required to confirm these results.

\section{Conflicts of interest}

The authors declare no conflict of interest.

\section{REFERENCES}

Arslan S, Pinarbasi H and Silig Y (2011). Myeloperoxidase G-463A polymorphism and risk of lung and prostate cancer in a Turkish population. Mol. Med. Rep. 4: 87-92.

Battisti V, Maders LD, Bagatini MD, Reetz LG, et al. (2011). Oxidative stress and antioxidant status in prostate cancer patients: relation to Gleason score, treatment and bone metastasis. Biomed. Pharmacother. 65: 516-524 http://dx.doi. org/10.1016/j.biopha.2011.06.003.

Bostwick DG, Alexander EE, Singh R, Shan A, et al. (2000). Antioxidant enzyme expression and reactive oxygen species damage in prostatic intraepithelial neoplasia and cancer. Cancer 89: 123-134. http://dx.doi.org/10.1002/10970142(20000701)89:1<123::AID-CNCR17>3.0.CO;2-9

Cheng TY, Barnett MJ, Kristal AR, Ambrosone CB, et al. (2011). Genetic variation in myeloperoxidase modifies the association of serum $\alpha$-tocopherol with aggressive prostate cancer among current smokers. J. Nutr. 141: 1731-1737. http://dx.doi.org/10.3945/jn.111.141713

Choi JY, Neuhouser ML, Barnett M, Hudson M, et al. (2007). Polymorphisms in oxidative stress-related genes are not associated with prostate cancer risk in heavy smokers. Cancer Epidemiol. Biomarkers Prev. 16: 1115-1120. http:// dx.doi.org/10.1158/1055-9965.EPI-07-0040

Choi JY, Neuhouser ML, Barnett MJ, Hong CC, et al. (2008). Iron intake, oxidative stress-related genes (MnSOD and MPO) and prostate cancer risk in CARET cohort. Carcinogenesis 29: 964-970. http://dx.doi.org/10.1093/carcin/ bgn056

Dally H, Gassner K, Jäger B, Schmezer P, et al. (2002). Myeloperoxidase (MPO) genotype and lung cancer histologic types: the MPO -463 A allele is associated with reduced risk for small cell lung cancer in smokers. Int. J. Cancer 102: 530-535.http://dx.doi.org/10.1002/ijc.10756

Ding G, Liu F, Shen B, Feng C, et al. (2012). The association between polymorphisms in prooxidant or antioxidant enzymes (myeloperoxidase, SOD2, and CAT) and genes and prostate cancer risk in the Chinese population of Han nationality. Clin. Genitourin. Cancer 10: 251-255.http://dx.doi.org/10.1016/j.clgc.2012.08.001

Forsberg L, Lyrenäs L, de Faire U and Morgenstern R (2001). A common functional C-T substitution polymorphism in the promoter region of the human catalase gene influences transcription factor binding, reporter gene transcription and is correlated to blood catalase levels. Free Radic. Biol. Med. 30: 500-505. http://dx.doi.org/10.1016/S0891$\underline{5849(00) 00487-1}$

Geybels MS, van den Brandt PA, van Schooten FJ and Verhage BA (2015). Oxidative stress-related genetic variants, pro- and antioxidant intake and status, and advanced prostate cancer risk. Cancer Epidemiol. Biomarkers Prev. 24: 178-186. http://dx.doi.org/10.1158/1055-9965.EPI-14-0968

Haque S, Mandal RK, Akhter N, Panda AK, et al. (2015). G894T and 4a/b polymorphisms of NOS3 gene are not associated with cancer risk: a meta-analysis. Asian Pac. J. Cancer Prev. 16: 2929-2937. http://dx.doi.org/10.7314/ APJCP.2015.16.7.2929

Heidenreich A, Bastian PJ, Bellmunt J, Bolla M, et al.; European Association of Urology (2014). EAU guidelines on prostate cancer. part 1: screening, diagnosis, and local treatment with curative intent-update 2013. Eur. Urol. 65: 124-137. http://dx.doi.org/10.1016/j.eururo.2013.09.046

Genetics and Molecular Research 15 (3): gmr.15038543 
Hu J, Feng F, Zhu S, Sun L, et al. (2015). Catalase C-262T polymorphism and risk of prostate cancer: evidence from metaanalysis. Gene 558: 265-270. http://dx.doi.org/10.1016/j.gene.2015.01.005

Karunasinghe N, Han DY, Goudie M, Zhu S, et al. (2012). Prostate disease risk factors among a New Zealand cohort. $J$. Nutrigenet. Nutrigenomics 5: 339-351. http://dx.doi.org/10.1159/000346279

Khandrika L, Kumar B, Koul S, Maroni P, et al. (2009). Oxidative stress in prostate cancer. Cancer Lett. 282: 125-136. http://dx.doi.org/10.1016/j.canlet.2008.12.011

Kiyohara C, Yoshimasu K, Takayama K and Nakanishi Y (2005). NQO1, MPO, and the risk of lung cancer: a HuGE review. Genet. Med. 7: 463-478.http://dx.doi.org/10.1097/01.gim.0000177530.55043.c1

Konishi N, Shimada K, Ishida E and Nakamura M (2005). Molecular pathology of prostate cancer. Pathol. Int. 55: 531539. http://dx.doi.org/10.1111/j.1440-1827.2005.01865.x

Lee KM, Kang D, Park SK, Berndt SI, et al. (2009a). Nitric oxide synthase gene polymorphisms and prostate cancer risk. Carcinogenesis 30: 621-625. http://dx.doi.org/10.1093/carcin/bgp028

Lee YC, Wu WJ, Liu CC, Wang CJ, et al. (2009b). The associations among eNOS G894T gene polymorphism, erectile dysfunction, and benign prostate hyperplasia-related lower urinary tract symptoms. J. Sex. Med. 6: 3158-3165. http:// dx.doi.org/10.1111/j.1743-6109.2009.01353.x

Møller H, Roswall N, Van Hemelrijck M, Larsen SB, et al. (2015). Prostate cancer incidence, clinical stage and survival in relation to obesity: a prospective cohort study in Denmark. Int. J. Cancer 136: 1940-1947.http://dx.doi.org/10.1002/ ijc. 29238

Nanni S, Aiello A, Re A, Guffanti A, et al. (2013). Estrogen-dependent dynamic profile of eNOS-DNA associations in prostate cancer. PLoS One 8: e62522. http://dx.doi.org/10.1371/journal.pone.0062522

Plata Bello A and Concepcion Masip T (2014). Prostate cancer epidemiology. Arch. Esp. Urol. 67: 373-382.

Polat F, Diler SB, Azazi İ and Öden A (2015). T-786C, G894T, and intron 4 VNTR (4a/b) polymorphisms of the endothelial nitric oxide synthase gene in bladder cancer cases. Asian Pac. J. Cancer Prev. 16: 2199-2202. http:// dx.doi.org/10.7314/APJCP.2015.16.6.2199

Rohrmann S, Linseisen J, Allen N, Bueno-de-Mesquita HB, et al. (2013). Smoking and the risk of prostate cancer in the European Prospective Investigation into Cancer and Nutrition. Br. J. Cancer 108: 708-714. http://dx.doi.org/10.1038/ bjc. 2012.520

Safarinejad MR, Safarinejad S, Shafiei N and Safarinejad S (2013). Effects of the T-786C, G894T, and Intron 4 VNTR $(4 \mathrm{a} / \mathrm{b})$ polymorphisms of the endothelial nitric oxide synthase gene on the risk of prostate cancer. Urol. Oncol. 31 : 1132-1140.http://dx.doi.org/10.1016/j.urolonc.2012.01.002

Shahabi A, Corral R, Catsburg C, Joshi AD, et al. (2014). Tobacco smoking, polymorphisms in carcinogen metabolism enzyme genes, and risk of localized and advanced prostate cancer: results from the California Collaborative Prostate Cancer Study. Cancer Med. 3: 1644-1655. http://dx.doi.org/10.1002/cam4.334

Tefik T, Kucukgergin C, Sanli O, Oktar T, et al. (2013). Manganese superoxide dismutase Ile58Thr, catalase C-262T and myeloperoxidase G-463A gene polymorphisms in patients with prostate cancer: relation to advanced and metastatic disease. BJU Int. 112: E406-E414. http://dx.doi.org/10.1111/bju.12176

Tong X and Li H (2004). eNOS protects prostate cancer cells from TRAIL-induced apoptosis. Cancer Lett. 210: 63-71. http://dx.doi.org/10.1016/j.canlet.2003.12.021

Vidal AC, Howard LE, Moreira DM, Castro-Santamaria R, et al. (2014). Obesity increases the risk for high-grade prostate cancer: results from the REDUCE study. Cancer Epidemiol. Biomarkers Prev. 23: 2936-2942. http://dx.doi. org/10.1158/1055-9965.EPI-14-0795

Wartenberg M, Schallenberg M, Hescheler J and Sauer H (2003). Reactive oxygen species-mediated regulation of eNOS and iNOS expression in multicellular prostate tumor spheroids. Int. J. Cancer 104: 274-282. http://dx.doi. org/10.1002/ijc.10928

Yu YP and Luo JH (2007). Pathological factors evaluating prostate cancer. Histol. Histopathol. 22: 1291-1300.

Zhang L, Chen LM, Wang MN, Chen XJ, et al. (2014). The G894t, T-786c and 4b/a polymorphisms in Enos gene and cancer risk: a meta-analysis. J. Evid. Based Med. 7: 263-269. http://dx.doi.org/10.1111/jebm.12126

Genetics and Molecular Research 15 (3): gmr.15038543 